\title{
21. Rewriting food insecurity narratives in Singapore
}

Al Lim

For many, the phenomenon of food insecurity can be reduced to a fundamental fear: what happens if I run out of food? People were made acutely aware of this fear at the start of the COVID-I9 pandemic in early 2020, when supermarkets began to run out of essentials. In Singapore, I propose that this fear was rooted in the narrative of scarcity and accelerated by the pandemic's crisis rhetoric. It extended a scarcity narrative developed since Singapore's independence, being an island nation cut off from Malaysia that had to survive with limited resources. Concurrently, this built on the neo-Malthusian logic seen in the Green Revolution of food scarcity as the main framing of the problem of hunger, instead of malnutrition and interconnected social issues. This way, the narrative obfuscated a more important statistic - I0.4\% of Singapore's population was still food insecure in 2020 (Nagpaul, Sidhu, and Chen 2020). ${ }^{\mathrm{I}}$

This chapter reframes Singapore's narrative of food insecurity away from a misapplied scarcity and securitisation lens, instead connecting food insecurity to the lived experience thereof. Engaging this challenge paves the way for key discussions about how food insecurity is not isolated but intersects with consumption and malnutrition through axes of inequality such as class, gender, climate, and race. Solely increasing food production has not been nor will be the solution to eradicating hunger, especially without attention to its wider social processes. This has vital implications for the current national strategy of ramping up food production and diversifying food sources. In the wake of the pandemic, it has become even more vital to consider the heterogeneity of Singapore's social body to ensure future foodscape policy decisions do not reproduce existing inequalities.

How to cite this book chapter:

Lim, Al. 2022. 'Rewriting food insecurity narratives in Singapore'. In: Shin, Hyun Bang; Mckenzie, Murray; and Oh, Do Young (eds) COVID-I9 in Southeast Asia: Insights for a post-pandemic world. London: LSE Press, pp. 239-248.

DOI: https://doi.org/I0.3 I389/lsepress.cov.u License: CC BY 4.०. 


\section{Constructing the strategic myth of food insecurity}

Food insecurity is not food scarcity. Eradicating scarcity or having excessive food supply does not mean that there is no food insecurity, as many may not receive food due to distribution channels, accessibility, or other confounding factors. So, why has this connection between insecurity and scarcity been constructed or accepted in Singapore? One way to account for this is that the scarcity narrative has been built on two powerful logics: the historical trope of Singapore's scarcity thinking since its inception and the neo-Malthusian, Green Revolution rationale.

Scarcity is ingrained in Singapore's ideology. The dominant narrative of scarcity and survival can be traced to modern Singapore's origins (Sadasivan 20I4). It is common knowledge in Singapore that the country began as a resource-scarce island that separated from Malaysia in the 1960 and, through a miraculous transformation, became a contemporary economic powerhouse. Part of this involved the state-invoked strategy of militarisation to ensure political tranquillity through perceptions of crises since the country's independence (Chong and Chan 2017, p.367; Tan 200I). The narrative legitimated drastic measures that the state needed to take, especially against those that might have seemed to come against it. Furthermore, crises stoke national sentiments. Consider how a government and population must do whatever it takes to ensure its success in an existential battle. Through the repeated invocation and naturalisation of scarcity-premised crises, this logic has remained dominant in contemporary Singaporean imaginaries.

To be sure, Singapore is a small island city-state and its resource scarcity cannot be wholly dismissed, but what must be explored further is whether the scarcity narrative is still appropriate. Singapore's position as a global city and top-ranked smart city, and its stellar economic profile, has placed the country in a radically different place from the I960s. The repeated strategy of invoking crises and the rationale of not having any natural resources has simplified a far more complex reality, a process that has served to enhance the state's political position. However, the use of the scarcity narrative in contemporary Singapore has faltered because it no longer stands for a corresponding reality, as the city does not face the same 'scarcity' that it did 60 years ago.

Singapore's historical penchant for scarcity blends with the neo-Malthusian, Green Revolution narrative of scarcity, food production, and demographic constraints. Thomas Malthus (I798) is known for his theory that the geometric-ratio (exponential) increase of the 
population would far exceed the arithmetic-ratio (linear) increase of food production, resulting in catastrophe when population outstrips food supply. The Malthusian link between population and food scarcity has been leveraged by proponents of the Green Revolution, claiming triumph over hunger and population woes through increased agricultural productivity. This connection was clearly stated when Norman Borlaug (I970) invoked the 'Population Monster' in his Nobel lecture, saying that the Green Revolution had only temporarily stemmed the tide against problems of human reproduction, where the scarcity of resource use remained the ultimate enemy.

However, the link between scarcity and hunger has been socially constructed and tenuous. As Amartya Sen (1983, p.8) has written, the 'mesmerizing simplicity of focusing on the ratio of food to population has persistently played an obscuring role over centuries'. The empirical evidence supports this and exposes the failures of this logic. While food production increased after the Green Revolution's implementation of 'miracle wheat' from its initial phases in Mexico in the I950s, the number of hungry people increased by more than i i \% in the decades of the Green Revolution's major advances (excluding China as an anomaly) (Rosset, Collins, and Lapp 2000). This finding questioned the success of the Green Revolution and challenged how increasing food supply and capacities do not necessarily reduce the problem of hunger and malnutrition. Moreover, critics of the Green Revolution have pointed out that it was a set of misguided technologies forced on developing nations - a form of American cultural imperialism - that disrupted rural patterns, cultivated patterns of dependency for seeds and chemicals, and caused largescale environmental degradation (Beeman and Pritchard 200I). While the Green Revolution has ended, its legacy has far from disappeared (Patel 20I3). The notion of not having enough (food scarcity) during COVID-I9 powerfully evoked and legitimated the need for increased food production, which has been the case for Singapore, despite little empirical support for the connection between food scarcity and hunger.

The two narratives of scarcity from Singapore's inception and the Green Revolution have combined to produce a strategic myth. This myth was not originally unfounded owing to strategic actions against material and resource constraints. Nevertheless, its continued usage has misapplied the logic of scarcity. The myth - an invocation of present-day food scarcity as food insecurity - no longer conformed to the reality of pandemic-era Singapore or the actions that it has legitimated, 
such as the heavy focus on agricultural innovation. In other words, the scarcity rationale from the post-independence narrative did not fit its contemporary Singaporean context, and resulting actions of increasing technological production must be critically reconsidered.

\section{'Security' and COVID-19 as catalysts}

The securitisation discourse and effects from the COVID-I9 pandemic also highlighted the urgency of food scarcity, amplifying this strategic myth. As a catalyst for this narrative, the 'security' aspect sharpened the need for apparent food production or diversifying food sources to address scarcity. The framing of securitisation relied on the construction of an external enemy, using the logic of survival, urgency, and defence as a necessary response to danger or risk (Sahu 20I9). This enabled the actors responsible to undertake whatever means necessary to fight the problem. In other words, the discursive focus on external food security relied upon, as security expert Naraghi-Anderlini (2020) has claimed, the belief that the deities of national security can never be questioned.

Ample evidence for securitising food security premised on addressing scarcity can be found in public discourse and reportage of COVID-I9 and food insecurity in Singapore. It was imperative to 'secure a supply of safe food for Singapore', according to the Singapore Food Agency (2019). This was reinforced by Minister of Trade and Industry Chan Chun Sing (2020) expressing how Singapore should not 'comprise our ability to secure such supplies from other sources by revealing our national stockpile'. Historically, Singapore had been 'buttressing' its food security for decades ( $\mathrm{Ng} 2020$ ), and it had now become 'every individual's fight' to maintain it (Tan 2020). The discursive repetition of securitised terms like 'security', 'fighting', 'buttressing', and 'stockpiling' framed Singapore's need to secure its food supply using military terminology. They became part of the country's naturalised and necessary discursive response to the pandemic.

The rhetoric of securitisation, along with uncertainty in the time of COVID-I9, complemented a set of strategic acts by the government. The Singaporean state adopted numerous measures to assuage public fears, such as Minister of Trade and Industry Chan Chun Sing posting pictures of 300,000 eggs arriving in March 2020. This emphasised the resilience of stockpiling strategies by national supermarket NTUC FairPrice, which avoided volatile price fluctuations and shortages. To further clarify what went on at the start of the pandemic, the state published an article that claimed that Singapore's food supply was 
never really at any risk and that it was an inter-agency effort between the Singapore Food Agency, the Ministry of Trade and Industry, Enterprise Singapore, and the Ministry of Foreign Affairs to ensure agri-trade was maintained through diverse and resilient mechanisms (Government of Singapore 2020). These public announcements complemented the Agri-Food and Veterinary Authority of Singapore's (2013) food security roadmap, which primarily focused on diversifying sources of imports, investing abroad, developing industry, producing locally, and stockpiling. The COVID-I9 pandemic resulted in an acceleration and expansion of these long-term plans for securitisation, as the state narrative remained resolute in its defence against food scarcity through a security modality.

\section{What about lived food insecurities?}

What the strategic myth and scarcity narratives missed was how food insecurity is a lived experience of hunger and malnutrition. It has been apparent that inequality exists in Singapore (Teo 20I7a). Specifically, inequality in domestic food consumption and security existed prior to COVID-I9. Based on the definition of food security in the World Food Summit (I996), all people at all times should have access to sufficient, safe, and nutritious foods to meet their dietary needs and food preferences for an active and healthy life. ${ }^{2}$ This was the working definition that the nationally representative survey of the Lien Centre for Social Innovation (LCSI) used, and the results indicated that $10.4 \%$ of Singaporean and permanent resident (PR) households had been severely $(3.5 \%)$ or moderately $(6.9 \%)$ food insecure in the previous I 2 months (Nagpaul, Sidhu, and Chen 2020).

These statistics were pre-pandemic, and COVID-I9 undoubtedly worsened them. Many of those who were food insecure lived in one- or two-room flats, and only $22 \%$ of food-insecure households were seeking support, due to social stigmatisation (Nagpaul, Sidhu, and Chen 2020). The pandemic's effects of lockdowns, economic and financial precarity, cabin fever, and compounding stresses increased the intensity and number of households facing food insecurity. Little representative data was available on the long-drawn-out effects of the pandemic, though social isolation served to reinforce the very boundaries preventing food-insecure households from reaching out in the first place. Therefore, the domestic portrayal of food insecurity, where not all people have access to adequate food at all times, was rendered less visible by the strategic myth of scarcity. 
The lived experience of food insecurity has also been fundamentally a question of health. Adverse health outcomes due to food insecurity have long been documented, affecting cognitive performance and being linked to higher risks of depression, anxiety, and cardiovascular risks such as hypertension and diabetes (Gundersen and Ziliak 20I 5 ; Seligman, Laraia, and Kushel 20II). The reduction in the comprehensive dietary requirements of food insecurity added to existing physical and mental health burdens from the pandemic.

These health tolls have also been unevenly distributed throughout the population along lines of inequality. The strategic myth has homogenised the population as benefiting wholesale from improved food production but has done little to unpack the disadvantages and other myths along axial intersections such as class and the climate disaster, as well as citizenship, gender, and race (Dutta 20I5; Teo 20I7a; Teo 20I7b).

\section{A new narrative of food insecurity}

As a direct response to COVID-I9, food production capacities ramped up, with urban farms becoming popular in the country. The increase in productive capacities was part of efforts to increase the domestic production of Singapore's nutritional needs from 10\% to $30 \%$ by 2030 (Teng 2020). This goal, along with the state's diversification strategies, was driven by the notion of scarcity and running out of food. To write against the strategic myth of food-insecurity-as-scarcity became an important endeavour, raising the critical question of: food security for whom?

Singapore does not need another Green Revolution and more scarcity thinking; food insecurity is not a simple, technocratic fix of production and supply. Addressing the problem of food insecurity must simultaneously account for its interconnected social processes, distribution channels, and the people consuming the food. Distributive channels and the 'who' can be illuminated by connecting it to community initiatives such as Eat for Good, Food from the Heart, and Foodbank's Feed the City. They continued to alleviate food insecurity during the lockdown and provided for families in need while supporting local businesses, and they should help to shape directions for addressing national food insecurity as vital stakeholders.

Better health and well-being outcomes for citizens during and beyond COVID-I9 are at stake. The pandemic thus played an expository role, bringing into sharp relief and exacerbating social inequalities like extant food security, as well as powerful ideologies like the scarcity 
narrative that undergird policy decisions. Considering the impact of the scarcity narrative, what narratives can Singapore rewrite? Indeed, with the series of wicked problems currently facing the island nation, what narratives must Singapore rewrite? For example, what happens if there is a shift from scarcity to frugality? Both acknowledge resource limits. Where the former evokes anxiety around the possibility of running out of resources, implying the need to securitise, the latter generates less anxiety while still maintaining the need for a more circumspect management of resources. This way, Singapore can mitigate the reproduction of mistakes that technology-as-salvation and neo-Malthusianism have wrought while creating more equitable foodways. Moreover, this chapter posits that being the 'top' in the world does not mean being free of problems, and other cities can undertake similar exercises to reflect on their own strategic myths, extant social inequalities, and the series of wider processes that the pandemic painfully exposed. Thus, to challenge inherited myths is also to enact more caring and careful modes of policymaking.

\section{Notes}

I. The statistic was released in a nationally representative survey by the Lien Centre for Social Innovation (LCSI) in August 2020, uncovering the hidden pockets of food insecurity in what the Economist Intelligence Unit (2019) had ranked as the most food-secure country in the world.

2 Compare this definition with how the Economist Intelligence Unit's (2019) ranked Singapore top in food security. The latter's three evaluative measures - affordability, availability, and quality and safety - are external components that pay little attention to the lived experiences of food insecurity. These indicators measure how resistant Singapore's food supply chain is to shocks, whether consumers have a wide variety of food to purchase at stable prices, and if the nutritional quality and safety of food are relatively high. The measures are determined by external factors such as economic tariffs, the amount invested in research and development, and the diversification of foods. While important, the definition can be integrated with a more expansive understanding of food security using the World Food Summit's definition.

\section{Acknowledgements}

Special thanks to Professor Sylvia Chant, Professor Michael Dove, Professor Paul Kockelman, Vanessa Koh, Jolene Lum, Isabelle Li, and the editors Professor Hyun Bang Shin, Dr Murray Mckenzie, and Dr Do Young Oh - for their generous contributions in shaping this chapter. 


\section{References}

Agri-Food and Veterinary Authority of Singapore. (2013). AVA's Food Security Roadmap for Singapore, Food for Thought. Singapore: Singapore Food Agency. https://perma.cc/APY3-A97L [Last accessed 20 September 2020].

Beeman, Randal S.; and Pritchard, James A. (200I). A Green and Permanent Land: Ecology and Agriculture in the Twentieth Century. USA: University Press of Kansas.

Borlaug, Norman. (I970). Acceptance Speech, on the Occasion of the Award of the Nobel Peace Prize in Oslo, Norway. https://perma.cc/TCA2-T6 3 [Last accessed 2I August 2020].

Chan, Chun Sing. (2020). Ministerial Community Walkabout at Jurong Spring Division, 9 February. https://perma.cc/R 5 CW-RYCL [Last accessed I9 August 2020].

Chong, Alan; and Chan, Samuel. (2017). 'Militarizing civilians in Singapore: preparing for "crisis" within a calibrated nationalism'. The Pacific Review, vol. 30, pp. 365-384. http://doi.org/I0.I080/095 I 2748.20I6.I 249906

Dutta, Mohan J. (201 5). Food Insecurity and Health of Bangladeshi Workers in Singapore: A Culture-Centered Study. Singapore: CARE White Paper Series, National University of Singapore. https://perma.cc/JM95-2JZE [Last accessed 20 August 2020].

Economist Intelligence Unit. (2019). 'Global Food Insecurity Index: Rankings and trends’. The Economist. https://perma.cc/76NC-J8PZ [Last accessed I 9 August 2020].

Government of Singapore. (2020). Food Security: It's Not Just about the Eggs. https://perma.cc/5TKK-RT9M [Last accessed 28 August 2020].

Gundersen, Craig; and Ziliak, James P. (2015). 'Food insecurity and health outcomes'. Health Affairs, vol. 34, pp. I830-1839. http://doi.org/IO.I377 /hlthaff.20I 5.0645

Malthus, Thomas. (1798). An Essay on the Principle of Population, as It Affects the Future Improvement of Society. UK: Printed for J. Johnson.

Nagpaul, Tania; Sidhu, Dalvin; and Chen, Jinwen. (2020). The Hunger Report: An In-Depth Look at Food Insecurity in Singapore. Singapore: Lien Centre for Social Innovation. https://perma.cc/K5 $\mathrm{B}_{4-5} \mathrm{ML} 6$ [Last accessed 16 September 2020].

Naraghi-Anderlini, Sanam. (2020). The COVID-I9 Crisis Response: Putting Women at the Centre. LSE Institute of Global Affairs, 29 April. https://perma .cc/TGT3-QM2A [Last accessed I9 August 2020]. 
Ng, Jun Sen. (2020). 'The big read: Singapore has been buttressing its food security for decades. Now, people realise why'. CNA, 23 March. https:// perma.cc/Z 5 FL-LJQT [Last accessed I9 August 2020].

Patel, Raj. (2013). 'The long green revolution'. The Journal of Peasant Studies, vol. 40, no. I, pp. I-63. https://doi.org/Io.I080/03066I 50.20I 2.7 I 9224

Rosset, Peter; Collins, Joseph; and Lapp, Frances Moore. (2000). 'Lessons from the green revolution: Do we need new technology to end hunger?' Tikkun Magazine, vol. I 5, no. 2, pp. 52-56. https://perma.cc/US 4 F-P9ET [Last accessed 17 September 2020].

Sadasivan, Viswa. (20I4). 'A narrative for winning', in Victor R. Savage (ed.) Singapore Challenged: The Uneasy and Unchartered Road Ahead, pp. I3-20. Singapore: National University of Singapore Society. https://perma

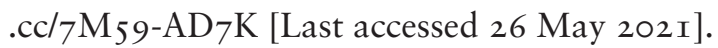

Sahu, Anjan Kumar. (2019). 'Referent object, securitising actors and the audience: The climate change threat and the securitisation of development in India'. Cambridge Review of International Affairs, pp. I-24. http://doi.org /IO.IO80/0955757I.20I9.I707509

Seligman, Hilary K.; Laraia, Barbara A.; and Kushel, Margot B. (2010). 'Food insecurity is associated with chronic disease among low-income NHANES participants'. The Journal of Nutrition, vol. I40, pp. 304-3 Io. http://doi.org /I0.3945/jn.I09.II 2573

Sen, Amartya. (1983). Poverty and Famines: An Essay on Entitlement and Deprivation. UK: Clarendon Press.

Singapore Food Agency. (2019). About SFA. https://perma.cc/R3VY-UGYP [Last accessed I9 August 2020].

Tan, Kenneth Paul Andrew Sze-Sian. (200I). 'Civic society and the new economy in patriarchal Singapore: Emasculating the political, feminizing the public. Crossroads: An Interdisciplinary Journal of Southeast Asian Studies, vol. I 5, pp. 95-I 22. https://perma.cc/M6TN-XN8U [Last accessed I7 August 2020].

Tan, Audrey. (2020). 'Safeguarding Singapore's food security at the national and household levels during coronavirus pandemic'. Straits Times, 8 April. https://perma.cc/N96D-59D7 [Last accessed I9 August 2020].

Teo, You Yenn. (2017a). This is What Inequality Looks Like. Singapore: Ethos Books.

Teo, You Yenn. (2017b). 'Poor people don't like oats either', in Kah Seng Loh, Ping Tjin Thum and Jack Meng-Tat Chia (eds) Living with Myths in Singapore, pp. 239-248. 
Teng, Paul. (2020). 'Assuring food security in Singapore, a small island state facing COVID-ı9'. Food Security, vol. I2, pp. I-4. http://doi.org/I0.1007 /SI 257 I-O20-0I077-0

World Food Summit. (I996). Rome Declaration on World Food Security. Rome: Food and Agriculture Organization of the United Nations. https:// perma.cc/P98L-DW 4 W [Last accessed 20 August 2020]. 